\title{
Spatial Patterns of Species Richness: A Hierarchical Per- spective
}

\section{JIANGUO WU WEI GAO}

Biological Sciences Center, Desert Research Institute University of Neveda System, Reno, NV 89506-0220, USA

(Received November 19, 1994)

\section{ABSTRACT}

This paper examines several major geographic patterns of species richness and related hypotheses of mechanisms. These species patterns include latitudinal gradient, elevation gradient, aridity gradient, species-area relationship, and microenvironmental pattern. Hypotheses and mechanisms to be examined include time hypothesis, origination-extinction dynamics hypothesis, available energy/productivity hypothesis, habitat heterogeneity hypothesis, moderate disturbance/ stress hypothesis, and niche theory/species interaction hypothesis. There has been a lack of conceptual frameworks to integrate biodiversity studies carried out at different spatial, temporal and organizational scales. We believe that such frameworks must take a hierarchical and scale perspective and explicitly consider the multiplicity of processes and mechanisms. In a rather concise fashion, we propose a hierarchical structure for relating both the patterns and hypotheses of species richness with spatial scales. This hierarchical framework helps to understand patterns, hypotheses and their relationship in terms of spatial scales and related processes. For example, patterns of species richness and responsible processes are usually scale-dependent. At continental and global scales, available energy in the environment seems to be the ultimate determinant of the number of species. However, other hypotheses must be invoked in order to satisfactorily explain the largescale patterns of species richness. Spatial heterogeneity and disturbance are significant at landscape or regional scales, whereas species interactions, disturbances, and microenvironmental factors operate most importantly on local scales.

\section{Introduction}

The study of the distributional patterns of species richness is an important step to understanding the relationship between biological diversity and underlying ecological factors and processes. This relationship is fundamental to conservation biology in general and the identification of stressors in particular (Noss 1990, Wu 1990, 1991, 1994). In particular, the distribution patterns of species richness found in natural or semi-natural ecological systems on different scales may serve as one kind of baseline conditions, against which changes in species richness can be detected in relation to anthropogenic stressors. Accordingly, stressors may be defined as factors and agents which affect the level and distributional pattern of species richness that are found in natural or semi-natural environment. In this paper, we shall discuss several major geographic patterns of species richness and related hypotheses of mechanisms. A hierarchical framework is then proposed to improve the understanding of the patterns and mechanisms and to facilitate the development of a more integrative theory of species richness.

- 12 • 


\section{Distributional patterns of species richness}

The pattern of species richness distribution in time and space has been a major theme in both ecology and biogeography for several decades. Several geographical patterns have been documented across a range of spatial scales. For terrestrial systems, the patterns include gradual, sometimes monotonic, changes in species richness along physical environmental gradients (e.g., latitude, elevation) on large scales, as well as more complex patterns that are determined by both local physical factors and biotic interactions on smaller scales. Here, we elucidate several major spatial patterns of species richness with related hypotheses that pertain to explain these patterns (cf. MacArthur 1965, Pianka 1966, MacArthur et al. 1967, Brown et al. 1983, Brown 1988, Orians 1994, Wu et al. 1994).

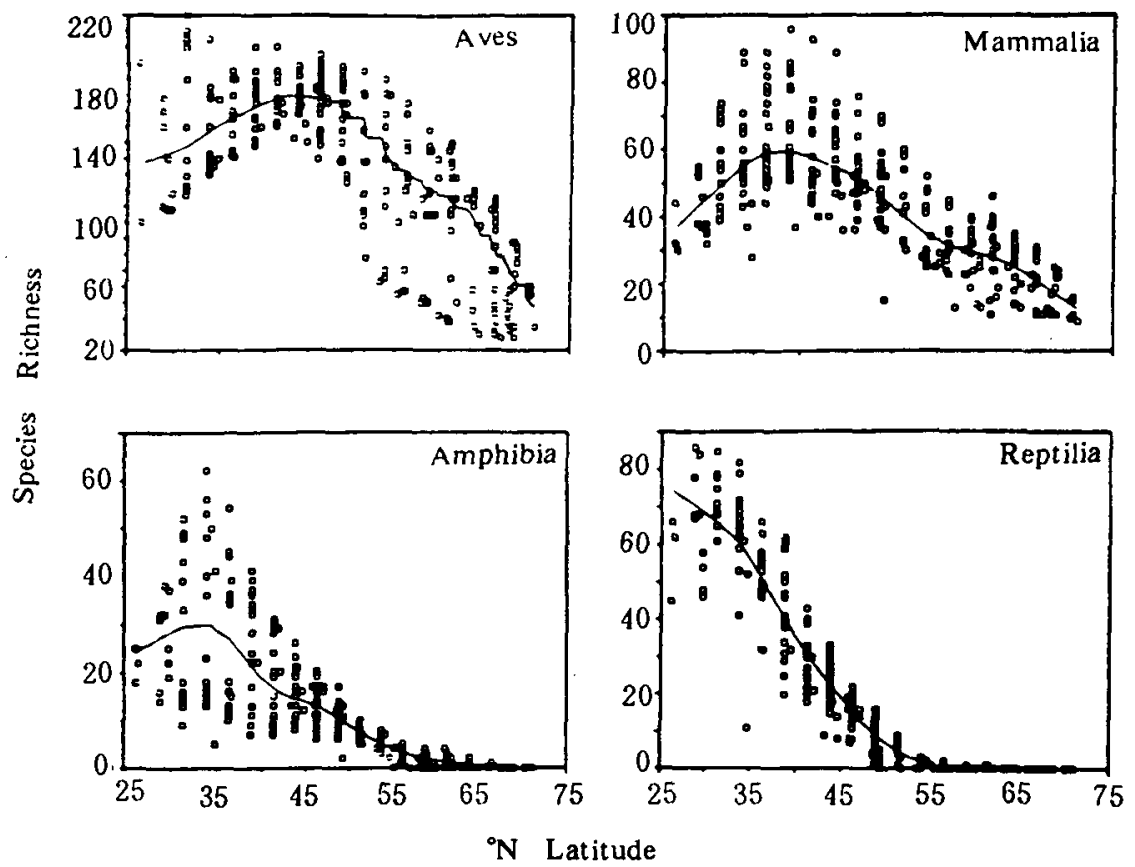

Fig. 1 The latitude gradients of species richness (from Currie 1991).

The number of species for different groups of organisms, in general, decreases with increasing latitude in the North Hemisphere. Notice, however, that the peaks in species richness for three of the four groups seem to occur around $35^{\circ} \mathrm{N}$ (Mammalia and Amphibia) or $45^{\circ} \mathrm{N}$ (Aves)

\subsection{Latitudinal gradient}

Species richness tends to decrease with increasing latitude from the equator to the poles, though the relationship is not monotonic for most taxonomic groups of organisms (Fig. 1). This pattern appears equally general for plants, animals, and microbes, and has been well documented in the literature (e. g. , Fischer 1960, Simpson 1964, Kiester 1971, Currie 1991).

\section{2 Elevation gradient}

Species richness decreases with increasing elevation for most.organisms (Fig. 2). The elevation gradient of species richness is also rather general, and has been fairly 
well documented ( Glenn-Lewin 1977, Brown 1988).

2. 3 Aridity gradient

Species richness decreases with increasing aridity across a geographic region or a continent. A striking example is that the number of plant species declines dramatically when one moves across the north-south oriented vegetation zones westward from the deciduous forest, to forest steppe, to typical steppe, and to desert in the temperate Eurasian continent. Aridity gradient often interacts with other gradients like elevation, which complicates the species richness patterns and their interpretation (Brown 1973, Whittaker et al. 1965, Glenn-Lewin 1977, Brown 1988).

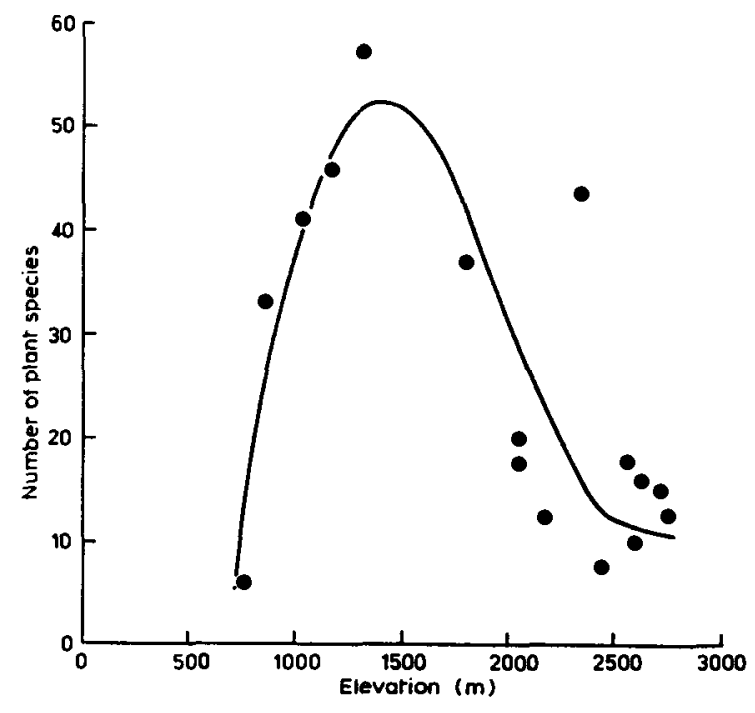

Fig. 2 The elevational gradients of species richness (from Brown 1988, orginal data from Whittaker et al. 1975).

\section{4 Species-Area relationship}

Species richness tends to increase monotonically with habitat area. A widely cited mathematical expression is of the form: $S=c A^{z}$, or, $\log S=z \log A+\log c$, where $S$ is species richness, $A$ is area, and $c$ and $z$ are positive constants. $c$ usually reflects the effect of geographical variation on species richness, and $z$ usually varies between 0.18 and 0. 35. This relationship has long been found in numerous studies of terrestrial community ecology and island biogeography (e. g. , Preston 1962, MacArthur et al. 1967; also see Wu 1989, Wu et al. 1994). The spatial scales on which this relationship is most likely to hold are from local communities to landscapes, and the effect of area on species richness seems to disappear on larger scales (see Currie 1991).

\section{5 Microenvironmental pattern}

Species richness exhibits gradient-like changes or more complex patterns on local, small scales in response to variations in abiotic and biotic environments. Numerous studies have demonstrated the importance of biological processes (e. g. , competition, predation, mutualism) on species richness through mechanisms such as niche differentiation and competitive exclusion (e. g. , Schoener 1974, Shmida et al. 1985, Auerbach et al. 1987, Tilman 1993). Spatial patterns of species richness correlated with local-scale physical environmental conditions (e. g., soil properties, micrometerological conditions) have been well documented for plant species (e. g., Goodall 1970, Wu 1992, Tilman et al. 1993), but much less for animals and microbes.

\section{Hypotheses and mechanisms of species richness patterns}

Several hypotheses that invoke various mechanisms have been proposed to explain 
the observed spatial patterns of species richness on different scales (see Pianka 1966, Loucks 1970, Brown et al. 1983, Brown 1988, Currie 1991). These include time, origination-extinction dynamics, available energy/productivity, habitat heterogeneity, disturbance, and niche theory/species interaction. In the following, we shall summarize these hypotheses by providing a concise description of their essential elements with a few relevant references. Then, a synthesis will be given based on a hierarchical and scale perspective.

\section{1 Time hypothesis}

Species richness increases with time because longer time allows both colonization and speciation to operate which in turn result in more diverse biotas (Fig. 3 ). This hypothesis has been applied on both ecological and evolutionary time scales .

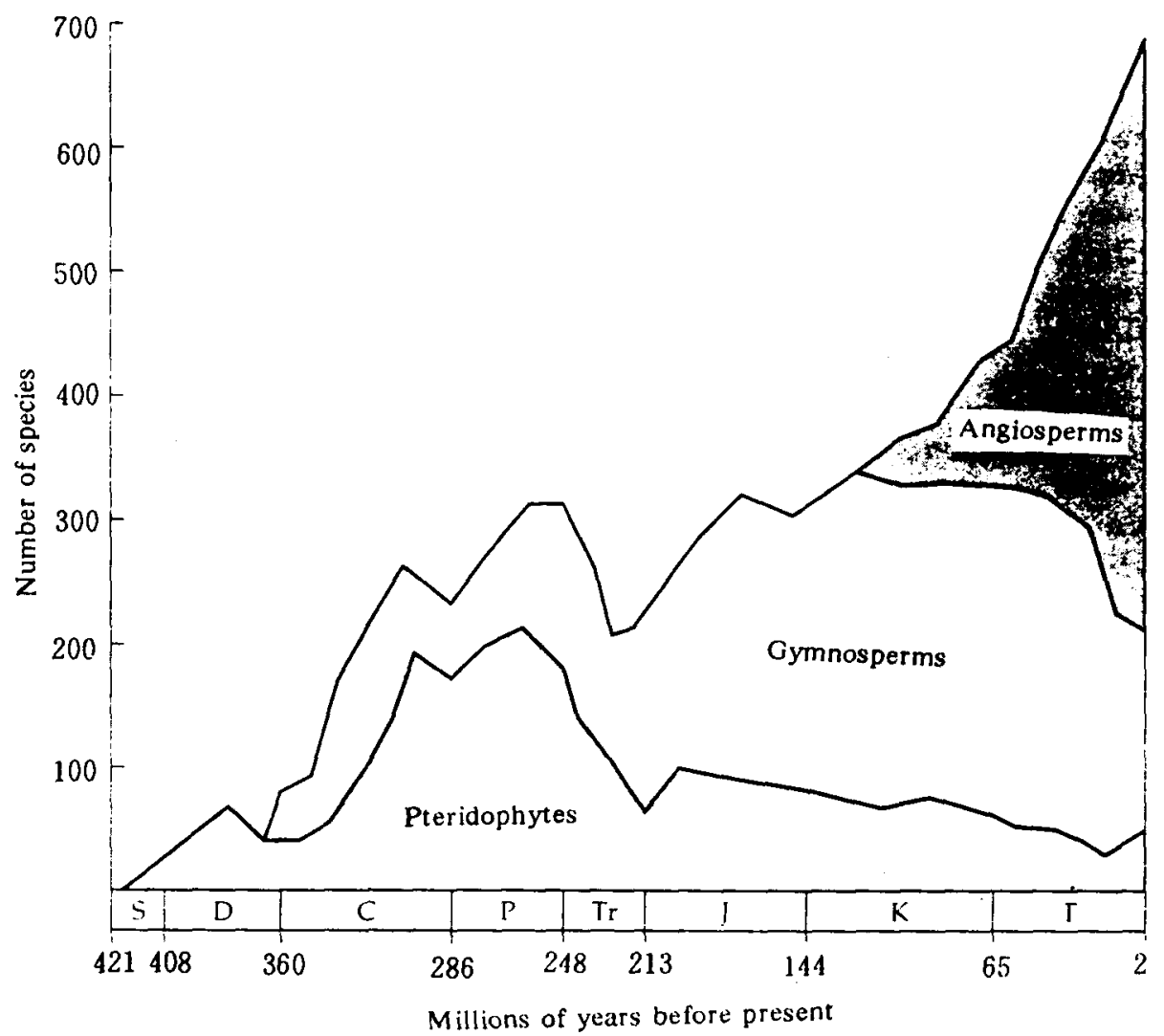

Fig. 3 The diversification of three groups of terrestrial plant species - ferns, gymnosperms, and angiosperms (from Orians 1994).

Time was first proposed as a hypothesis to explain the decrease in species richness with increasing latitude, in which tropical areas were thought to have more time to diversify because of the absence of the glaciation that took place at temperate latitudes (e. g. , Fischer 1960). However, it is difficult to test the hypothesis on evolutionary or geological time scales. At local spatio-temporal scales, it seems generally acceptable that the longer the time since last disturbance, the more species are likely to colonize.

3. 2 Origination-extinction dynamics hypothesis 
species richness is a result of the balance between species origination (colonization and speciation) and extinction, and, therefore, the patterns of species richness may be explained by the differences in these processes. This hypothesis also involves both ecological and evolutionary times, and has been used to explain species richness patterns from the local community to the continental and global levels (MacArthur et al. 1967, Benton 1987, Brown 1988). On ecological time scales, the theory of island biogeography asserts that the number of species in insular habitats is determined primarily by colonization and extinction rates which in turn are affected by habitat area and distance to the colonizing source (MacArthur et al. 1967). While the theory has been criticized on several grounds, there have been many studies of oceanic and terrestrial habitat islands supporting the basic idea of colonization-extinction dynamics (Wu 1989, Wu et al. 1994). There has been little direct evidence, however, for the applicability of this hypothesis at continental and global scales or on evolutionary and geological times (Benton 1987, Brown 1988).

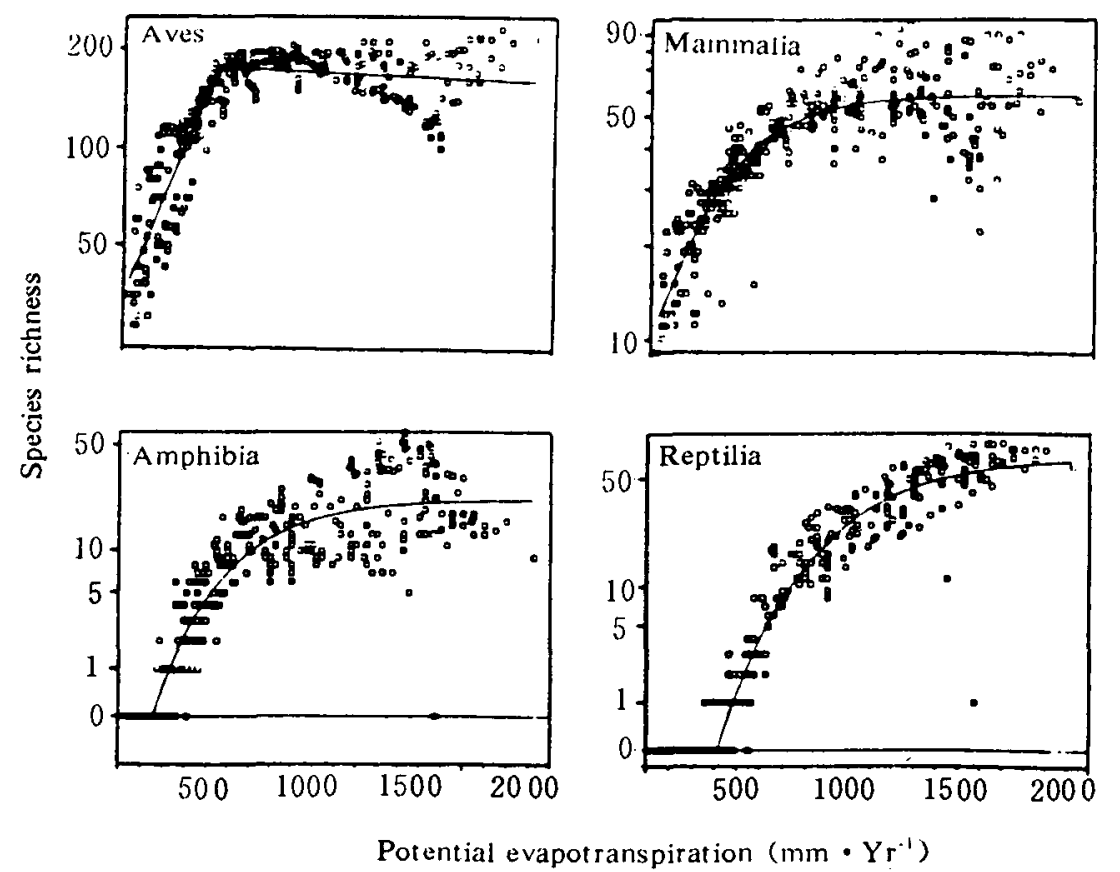

Fig. 4 The relationship between potential evapotranspiration and the species richness of four vertebrate classes- birds, amphibians, mammals, and reptiles (from Currie 1991).

\section{3 Available energy/productivity hypothesis}

Species richness proliferates with increasing energy availability in the environment. At regional and continental scales, it has been shown that species richness is a function of available energy or primary productivity (Wright 1983, Currie 1991, Hall 1991). Based on the species-area relationship and the equilibrium theory of island biogeography, Wright (1983) developed a "species-energy theory." The core of the theory is represented by the mathematical formulation, $S=k E^{*}$, where $S$ is the species richness, $E$ is the total production of available energy, and $k$ and $z$ are constants. Wright (1983) 
found that available energy, measured as total actual evapotranspiration (AET) for angiosperms and total net primary production (NPP) for breeding land and freshwater birds, was able to account for $70 \sim 80 \%$ of the variation in species richness on islands ranging from Greenland and Spitsbergen to New Guinea and Jamaica. Currie (1991) demonstrated that, for the four vertebrate classes in North America he studied (birds, mammals, amphibians, and reptiles), annual potential evapotranspiration (PET) alone accounted for $80 \sim 90 \%$ of the variability in species richness (Fig. 4). In addition, available energy häs been shown to be the best predictor of decomposition rate at continental and global scales (Meentemeyer 1984). At smaller scales, on the other hand, empirical studies (especially in plant community ecology) have shown that species richness decreases with increasing community porductivity (e. g. , Rosenzweig 1968, Tilman 1982, 1993 ). Therefore, the interpretation of the hypothesis and mechanisms involved are both scale-dependent.

3. 4 Habitat heterogeneity hypothesis

Species richness increases with habitat heterogeneity which reflects the diversity and variability in the structure, function and dynamics of the environment organisms live in. Among the first, Williams (1964) asserted that the species-area relationship results from a positive correlation existing between area and habitat diversity and between habitat diversity and species diversity. High habitat heterogeneity usually supports more species by providing more habitat types and reducing local extinctions caused by adverse biotic interactions such as competition and predation. There has been ample supporting evidence for the habitat heterogeneity-species richness relationship (Cody 1974, Tilman 1993, Shmida et al. 1985, Boecklen 1986). Recent studies of patch dynamics have provided new insight into the relationship between spatial heterogeneity on species richness by emphasizing the interactions between pattern and process at population and community levels (Steele 1978, Pickett et al. 1985, Aerbach et al. 1987, Levin et al. 1993, Wu et al. 1994).

\section{5 Moderate disturbance/stress hypothesis}

The highest species richness usually occurs where disturbance or stress is intermediate. Disturbance often creates structural and functional heterogeneity in time and space, and promotes the coexistence of species by directly suppressing destabilizing biotic interactions (e.g., intense interspecific competition and predation) or by providing regeneration niches. A number of empirical and theoretical studies on scales from local communities to regional landscapes support this notion (e. g. , Grime 1973, Connell 1978, Loucks 1970, Suffing et al. 1988). However, the terms "moderate" and "intermediate" seem ambiguous and, therefore, have been used largely in a qualitative sense. 3. 6 Niche theory/species interaction hypothesis

Species richness in a biotic community is a function of the number of niches ; interspecific interactions such as competition, predation, and mutualism, may promote species proliferation through modifying niche relations. The study of interactions between species diversity and niche relations has been a central theme in both theoretical and field community ecology for the past several decades (e. g. , Schoener 1974, Krebs 1985 ). In particular, it has been suggested that interspecific competition facilitates niche differentiation, while predation reduces competition among prey species which in turn reduces the probability of competitive exclusion (e.g. , Paine 1966, Connell 1978, 


\section{Brown 1988).}

The above hypotheses are not mutually exclusive, but are complimentary to each other. Evidence supporting one hypothesis does not imply that others are not as valid. Indeed, multiple hypotheses are usually necessary to better account for an observed species distribution pattern. In most cases, each hypothesis represents only one of several levels of explanation (Brown 1988). On the other hand, overlap among some of the hypotheses is evident. For example, time, be it ecological or evolutionary, is critical in the origination-extinction dynamics hypothesis since dispersal and speciation are considered essential. Also, the hypotheses about habitat heterogeneity, disturbance, and niche theory/species interactions are interrelated conceptually and practically. Disturbance is important in both creation and maintenance of spatial heterogeneity, whereas spatial heterogeneity may significantly affect the disturbance regime (Pickett et al. 1985). Both habitat heterogeneity and disturbance interact with species and population dynamics. In concert, these three hypotheses may account for many if not most species richness patterns on small scales. The interaction among the three hypotheses is best exemplified by the regeneration niche theory which has been evidenced by numerous studies at the community level (Grubb 1977, Pickett et al. 1985, Wu et al. 1994).

\section{Concluding remarks}

One of the problems in the study of biological diversity has been the lack of a conceptual framework to integrate information obtained from numerous ecological and biogeographical observations on a wide range of scales. Available energy and its allocation across different organizational levels may serve as a basis for developing a general theory of species richness (see Brown 1981, Wright 1983, Currie 1991, Hall 1991). Towards this end, Hall (1991) has recently developed an integrative framework for the distribution and abundance of organisms using energy cost and gain analysis. Importantly, any general theory must take a hierarchical and scale perspective, and should explicitly consider the multiplicity of processes and mechanisms that operate on different temporal, spatial and organizational levels. Based on previous studies, we propose a hierarchical structure to relate both the patterns and hypotheses of species richness to spatial scales which are categorized into local, regional, and continental/global domains (Fig. 5).

It is important to notice that a particular pattern of species richness usually occurs over a certain range of spatial scales, and that different patterns and mechanisms should be expected on disparate scales. In other words, the hypotheses of mechanisms regarding species richness patterns have to be scale-dependent. In particular, at very large (e. g. , continental or global) scales, the available energy in the environment seems to be the ultimate determinant of the number of species, although the specific measure of available energy may vary with taxonomic groups (see Wright 1983, Currie 1991). That is, the maximum or potential species richness is constrained by energetics on large scales. Brown (1981) conveyed essentially the same idea using the term "capacity rules." However, to fully explain the large-scale patterns of species richness, other hypotheses such as time and origination-extinction dynamics must be invoked, because processes like colonization and speciation take time and history can be just as important as anything else.

$\cdot 18 \cdot$ 


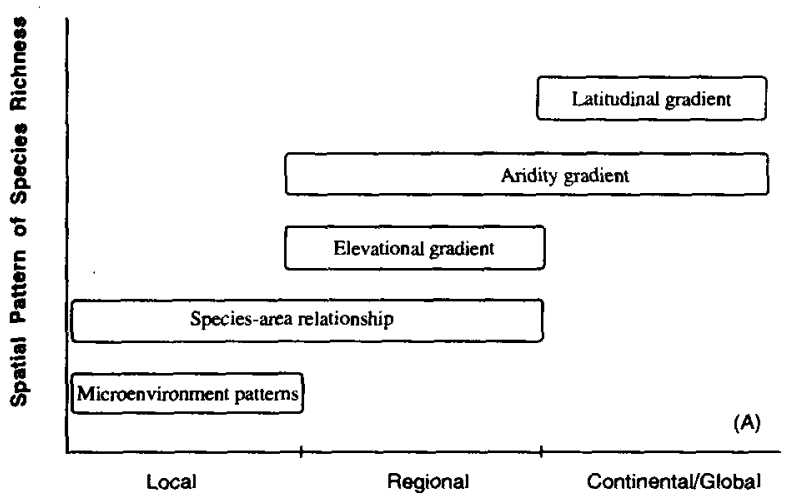

Fig. 5 The relationship between the patterns and hypotheses of species richness and the domains of spatial scale on which they operate: (A) observed geographic patterns of species richness, and (B) hypotheses of mechanisms that have been used to explain the patterns.

The range for the patterns to occur and for the hypotheses to apply mostly goes beyond one of the three broadly categorized spatial domains. However, some of them do seem to operate primarily on one (e. g. , latitudina: and microenvironmental gradients and niche relations hypothesis). Information on the various gradients and hypotheses of species richness is based mainly on Brown (1981, 1988), Auerbach and Shmida (1987), and Currie

(B) (1991)

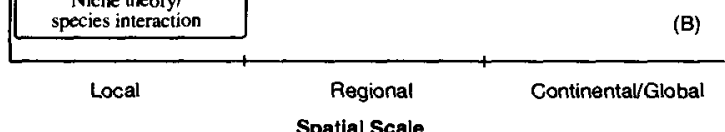

The number of species on smaller scales, on the other hand, is primarily determined by energy partitioning and balance. This is consistent with Brown's (1981) concept of "allocation rules". Any factors and processes that affect the energy allocation among species thus may influence the distribution of species richness. On landscape or regional scales, spatial heterogeneity and disturbance are important, whereas on local scales species interactions, disturbances, and microenvironmental factors most likely become the determinants of species richness. Indeed, the pluralism in mechanisms and multiplicity in scale may have been significant sources of controversy and confusion in the study of species richness in particular and biodiversity in general. A hierarchical approach as illustrated here may facilitate the examination of the relationships among different patterns and mechanisms and, therefore, the development of a more comprehensive understanding of species richness.

\section{ACKNOWLEDGMENTS}

We thank Orie L. Loucks, Dennis Jelinski, and James Wickham for their comments and suggestions on an earlier version of the manuscript. This paper was presented at the First National Symposium on the Conservation and Sustainable Use of Biodiversity, Beijing, China, Sept. 15 17, 1994. 


\section{REFERENCES}

Auerbach M, A Shmida, 1987. Spatial scale and the determinants of plant species richness. Tree, 2, 238 $\sim 242$

Benton $\mathrm{M} \mathrm{J}, 1987$. The history of the biosphere: Equilibrium and non-equilibrium models of global diversity. , Tree, 2:153 156

Boecklen W J, 1986. Effects of habitat heterogeneity on the species-area relationships of forest birds. J. Biogeogr. , 13:59 68

Brown J H, 1973. Species diversity of seed-eating desert ordents in sand dune habitats. Ecology, 54: 775 787

Brown J H, 1981. Two decades of Homage to Santa Rosalia: Toward a general theory of diversity. Amer. Zool. 21:877 888

Brown J H, 1988. Species diversity. In: Myers A A, P S Giller (eds.), Analytical Biogeography, London: Chapman and Hall, 57 89

Brown J H, A C Gibson, 1983. Biogeography. Mosby, St. Louis

Cody M L, 1974. Competition and the structure of bird communities. Princeton: Princeton University Press

Connell J H, 1978. Diversity in tropical rainforests and coral reefs. Science, 199:1302 1310

Currie D J, 1991. Energy and large-scale patterns of animal- and plant-species richness. Am. Nat. , 137: $27 \sim 49$

Fischer A G, 1960. Latitudinal variations in organic diversity. Evolution, 14:64 81

Glenn-Lewin D C, 1977. Species diversity in North American temperate forests. Vegetatio, 33:153 162

Goodall D W, 1970. Statistical Plant Ecology. Annu. Rev. Ecol. Syst., 1: 99 124

Grime J P, 1973. Competitive exclusion in herbaceous vegetation, Nature, 242:344 347

Grubb P J, 1977. The maintenance of species richness in plant communities: The importance of the regeneration niche. Biol. Rev., 52:107 145

Hall C A S, 1991. The distribution and abundance of organisms as a consequence of energy balances along multiple environmental gradients. Oikos, 61

Kiester R A, 1971. Species density of North American amphibians and reptiles. Syst. Zool., 20:127 157

Krebs C J, 1985. Ecology: The experimental analysis of distribution and abundance. 3rd ed. New York: Haper and Row

Levin S A, T Powell, J H Steele (eds), 1993. Patch dynamics. New York: Springer-Verlag

Loucks O L, 1970. Evolution of diversity, efficiency, and community stability. Am. Zool., 10:17 25

MacArthur R H, 1965. Patterns of species diversity. Biol. Rev. , 40:510 533

MacArthur R H, E O Wilson, 1967. The Theory of Island Biogeography. Princeton: Princeton University Press

Meentemeyer V, 1984. The geography of organic decomposition rates. Annals Assoc. Am. Geogr., 74, $551 \sim 560$

Noss R F, 1990. Indicators for monitoring biodiversity: A hierarchical approach. Conserv. Biol., 4: $355 \sim 364$

Orians G H, 1994. Global biodiversity I : patterns and processes. In : Meffe G K, C R Carroll (eds). Principles of Conservation Biology. Sunderland: Sinauer Associates, 78 109

Pianka E R, 1966. Latitudinal gradients in species diversity : A review of concepts. Am. Nat. , 100:33 $\sim 46$

Pickett S T A, P S White (eds), 1985. The Ecology of Natural Disturbance and Patch Dynamics. New York: Academic Press

Preston F W, 1962. The canonical distribution of commonness and rarity. Ecology, 43:185 215, 410 $\sim 432$

- 20 . 
Rosenzweig M L, 1968. Net primary productivity of terrestrial communities : Prediction from climatological data. Am. Nat. , 102:67 74

Schoener T W, 1974. Resource partitioning in ecological communities. Science, 185:27 39

Shmida A, M V Wilson, 1985. Biological determinants of species diversity. J. Biiogeogr. , 12:1 20

Simpson, G G, 1964. Species density of North American recent mammals. Syst. 2'.ool. , 13:57 73

Steele J H(ed. ), 1978. Spatial Patterns in Plankton Communities. New York: Plenum Press

Suffling R, C Lihou, Y Morand, 1988. Control of landscape diversity by catastrophic disturbance : A theory and a case study of fire in a Canadian boreal forest. Environ. Management, 12:73 78

Tilman D, 1993. Species richness of experimental productivity gradients ; How important is colonization limitation? Ecology, 74:2179 2191

Tilman D, S Pacala, 1993. The maintenance of species richness in plant communities. In : R Ricklefs, D Schluter (eds.), Species Diversity in Ecological Communities. Chicago : University of Chicago Press

Whittaker R H, W A Niering, 1965. Vegetation of the Santa Catalina Mountains, Arizona : A gradient analysis of the south slope. Ecology, 46:429 452

Williams C E, 1964. Patterns in the balance of nature and related problems in quantitative ecology. New York: Academic Press

Wright D H, 1983. Species-energy theory: An extension of species-area theory. Oikos, 41:496 506

Wu J, 1989. The theory of island biogeography : models and applications. $J$. Ecol. (CHN), 8(6):34 39

Wu J, 1990. Nature conservation theory and MacArthur-Wilson model. Acta Ecologica Sinica, 10(2): $187 \sim 191$

Wu J, 1991. Dissipative structure, hierarchy theory and ecosystems. J. Appl. Ecol. (CHN), 2:181 186

Wu J, 1992. Detecting spatial patterns : the net-function interpolation. Coenoses, 7(3):137 143

Wu J, 1994. Modeling dynamics of patchy landscapes : linking metapopulation theory, landscape ecology and conservatin biology. The Yearbook of the Department of Systems Ecology, Beijing: Chinese Academy of Sciences

Wu J, S A Levin, 1994. A spatial patch dynamic modeling approach to pattern and process in an annual grassland. Ecological Monographs, 64(4): 447 464

Wu J, J L Vankat, 1991. A system dynamics model of island biogeography. Bull. Math. Biol., 53: $911 \sim 940$

Wu J, J L Vankat, 1994. Island biogeography: Theory and applications. Encyclopedia of Environmental Biology, New York : Academic Press 